\title{
The efficacy of twin block in increasing the mandibular length: A cephalometric study
}

\author{
Anil Dhingra ${ }^{1, *}$, RPS Bedi' ${ }^{2}$, Amit Jain ${ }^{3}$ \\ ${ }^{1}$ Consultant \& Command Dental Advisor, Command Military Dental Center (NC), Udhampur, Jammu \& Kashmir, ${ }^{\mathbf{2 , 3}}$ Classified \\ Specialist \& Corps Dental Advisor, Corps Dental Unit, Jammu \& Kashmir, India
}

*Corresponding Author:

Email: dranildhingra@yahoo.co.in

\begin{abstract}
Introduction: Angle's Class II Div 1 malocclusion is one of the most common malocclusions in orthodontics. In cases of Angle's Class II Div 1 malocclusion with mandibular deficiency, myofunctional appliances are often used with the intent of stimulating mandibular growth. Twin block is one of the most popular myofunctional appliances.

Aim: The aim of this study was to find out "Does the length of mandible increase with Twin Block appliances" using cephalometric radiograph.

Materials and Methods: Cephalometric radiographs of 15 patients who had Class II Div I malocclusion, before and after treatment were examined. The mean changes after Twin Block were compared with pre-treatment parameters using independent' $t$ ' test.

Results: There were statistically significant differences in Pre and Post-treatment mandibular length. Patients treated with twin block appliance showed a mean increase of $4 \mathrm{~mm}$ in the mandibular length.

Conclusion: Twin Block is an effective myofunctional appliance which can be used to increase the effective mandibular length in patients with skeletal Class II Div I malocclusion.
\end{abstract}

Keywords: Functional appliance, Class II malocclusion, Twin block.

\section{Introduction}

Angle's Class II malocclusion is one of the most common orthodontic problem that affects about a third of all subjects seeking orthodontic treatment. ${ }^{1,2}$ There are several treatment options for the management of this problem; but functional appliances have been used for over a century in the treatment of Class II Division 1 malocclusions. Although few clinicians deny their clinical efficacy, concrete proof of their growth modifying effect remains elusive.,

In cases with Class II malocclusion due to mandibular deficiency, functional appliances often are used with the focus of stimulating mandibular growth. Various studies have been conducted to see the effect of functional appliances on growth of mandible. Studies by Bjork ${ }^{5}$ and Pancherz ${ }^{6}$ have demonstrated that there were only small changes in mandibular length and they have concluded that functional appliance treatment did not affect any change in mandibular length. In contrast Harris $^{7}$ DeVincenzo ${ }^{8}$ and Windmiller ${ }^{9}$ have concluded that there was significant influence on mandibular growth on timely intervention with functional appliances.

However, some authors claim that the most significant treatment effects of functional appliances are restricted to dentoalveolar changes ${ }^{10}$ because these appliances are tooth supported, rather than bone supported $^{3}$. So, the actual effects of functional appliances remain controversial as most of the studies typically do not distinguish between dental and skeletal components of the correction.
According to Robertson ${ }^{11}$ the effect of functional appliances was dentoalveolar, which included distalization of the upper molar and retroclination of upper incisors, along with mesial movement of the lower molars and proclination of the lower incisors. Vertical changes induced were attributed to inhibition of eruption of the maxillary molars and enhanced eruption of the mandibular molars. ${ }^{12,13}$

Tulloch et al. ${ }^{14}$ systematically reviewed studies over a seven-year period in four major orthodontic journals that report on the treatment of Class II malocclusions with functional appliance. Failure to test for pre-treatment equivalence, poor sample sizes, poor research designs, inappropriate selection of subjects and ambiguous \& incomplete reporting made interpretation of the results difficult and their scientific validity questionable.

Individually, many studies ${ }^{15-20}$ have found changes in mandibular length and position, both in the sagittal and vertical plane. However, when studies are grouped and analyzed together in systematic reviews and metaanalysis, controversies appear. Some reviews like Cozza et al. ${ }^{1}$ have found no statistically or clinically significant differences between groups treated with functional appliances and controls, while others like Marsico et $\mathrm{al}^{21}$ have observed those differences to be statistically significant. Additionally, D'Anto et al. ${ }^{22}$ have found statistically significant mandibular elongation on treatment with functional appliances.

Systematic review by Cozza et al. ${ }^{1}$ evaluated the effects of different functional appliances on mandibular length. Both removable and fixed functional appliances 
were included in the review. The combination of removable and fixed appliances in the systematic review, masked the true interpretation of the results by different appliances.

The aim of this study was to assess the changes in mandibular length as a result of usage of Twin Block appliance with the help of cephalometric radiographs.

\section{Materials and Methods}

The present study was conducted on pre-treatment and post-treatment records of 15 cases with Angle's Class II div 1 malocclusion treated using Twin Block appliance. The sample was drawn from the fifty cases of Angle's Class II Div 1 malocclusion based on inclusion and exclusion criteria. Only those cases having complete pre-treatment and post-treatment records were included in the study, fifteen cases fulfilled the selection criteria.

The following inclusion and exclusion criteria were followed while selecting the cases for the study:

\section{Inclusion Criteria}

1. Chronologic age between 10-14 years.

2. Skeletal Class II malocclusion with ANB $>5^{\circ}$.

3. Overjet between 5 to $15 \mathrm{~mm}$.

4. Complete pre and post treatment records.

5. Horizontal growth pattern.

\section{Exclusion Criteria}

1. Maxillary prognathism.

2. Severe protrusion of maxillary incisors

3. Severe dental crowding (space deficiency more than $4 \mathrm{~mm}$ ).

4. Anterior dental open bite.

5. Previous orthodontic treatment.

6. Extracted permanent teeth

All the cephalograms used for the study were traced manually on a standard cellulose acetate paper of 8 "x 10 " size and 0.003 " thickness by using a hard $3 \mathrm{H}$ pencil under standard illumination. All the cephalograms were traced by the same investigator with a standard technique. The angular measurements were measured manually by protractor with least count of $0.5^{\circ}$ and all the linear measurements were recorded using metallic scale with $0.5 \mathrm{~mm}$ precision.

Cephalometric parameters considered were: SNA, SNB, ANB, Wits Appraisal, SN-MP, U1-NA, L1-NB, U1-L1, Co-Gn, Co-Point A, Max-M and differential.

\section{Measurement of cephalometric error}

Error due to fatigue: Two cephalograms were analysed on an average in a day to eliminate the error due to fatigue of the investigator.

Intra-observer error: The assessment of intraobserver variability and reproducibility of landmark location and measurement errors were analysed by retracing the $10 \%$ randomly selected cephalograms after a gap of 15 days. The method error was calculated according to Dahlberg formula.

The statistical analysis was performed using statistical package for social sciences (SPSS Inc., Chicago, IL, version 17.0 for Windows). All the data was recorded and analysed for mean and standard deviation or median. The mean changes by use of Twin Block appliance pre-treatment and post-treatment were compared using independent ' $t$ ' test. Statistical significance was set at $\mathrm{p}<0.05$.

\section{Results}

The present cross-sectional study was conducted on pre-treatment and post-treatment records of 15 cases with Angle's Class II div 1 malocclusion treated with Twin Block appliance. The mean age of the subjects at the beginning of study was $12.56 \pm 0.91$. The posttreatment lateral cephalometric analysis showed skeletal improvement in Class II malocclusion such as reduction in ANB angle by $3.66^{\circ}$, Wits by $3.46 \mathrm{~mm}$ and an increase in mandibular plane angle SN-MP by $1.26^{\circ}$.

The maxillary incisor proclination was improved with retroclination of upper incisor (U1 to NA by $4^{\circ}$ ), and the mandibular incisor proclination was increased (L1 to NB by $4.6^{\circ}$ ) as shown in Table 1 .

The post-treatment lateral cephalometric analysis showed that the mean increase in mandibular length was $4.0 \mathrm{~mm}$ and mean reduction in maxillary length was $0.33 \mathrm{~mm}$. It demonstrated skeletal improvement in Class II malocclusion as shown in Table 2.

The mandibular unit length (measured from condylion to gnathion) increased by $4 \mathrm{~mm}$. It was not possible to determine whether the increase in Co-Gn was due to an increase in mandibular length or a repositioning of the mandible. No actual measurement of fossa adaptation or relocation was made in the study. Statistical analysis is reflected in Table 3.

Table 1: Cephalometric measurements

\begin{tabular}{|l|c|c|c|}
\hline \multicolumn{1}{|c|}{ Measurement } & Normal & Pre-treatment $(\mathbf{n = 1 5})$ & Post-treatment $(\mathbf{n = 1 5})$ \\
\hline $\mathrm{SNA}\left({ }^{\circ}\right)$ & 82.0 & 84.00 & 83.53 \\
\hline $\mathrm{SNB}\left({ }^{\circ}\right)$ & 80.0 & 77.80 & 80.93 \\
\hline $\mathrm{ANB}\left({ }^{\circ}\right)$ & 2.0 & 6.26 & 2.60 \\
\hline Wits(mm) & 0.0 & 5.13 & 1.66 \\
\hline $\mathrm{SN}-\mathrm{MP}\left({ }^{\circ}\right)$ & 32 & 26.80 & 28.06 \\
\hline $\mathrm{U} 1-\mathrm{NA}\left(^{\circ}\right)$ & 22 & 31.93 & 29.83 \\
\hline $\mathrm{L} 1-\mathrm{NB}\left({ }^{\circ}\right)$ & 25 & 22.13 & 25.73 \\
\hline $\mathrm{U} 1-\mathrm{L} 1\left(^{\circ}\right)$ & 131 & 113.75 & 124.50 \\
\hline
\end{tabular}


Table 2: Cephalometric measurements (Mandibular growth)

\begin{tabular}{|l|c|c|}
\hline \multicolumn{1}{|c|}{ Measurement } & Pre-treatment $(\mathbf{n = 1 5})$ & Post-treatment $(\mathbf{n}=15)$ \\
\hline Mand length $($ Co-Gn) $(\mathrm{mm})$ & 94.40 & 98.40 \\
\hline Max length $($ Co-Point A) $(\mathrm{mm})$ & 77.93 & 78.26 \\
\hline Max-Mand differential $(\mathrm{mm})$ & 16.46 & 20.20 \\
\hline
\end{tabular}

Table 3: Statistical analysis: Paired Sample ' $t$ ' Test

\begin{tabular}{|l|l|l|l|l|l|l|l|}
\hline & & Mean & $\begin{array}{l}\text { Std. } \\
\text { Deviation }\end{array}$ & $\begin{array}{l}\text { Std. Error } \\
\text { Mean }\end{array}$ & t & Sig. (2 tailed) \\
\hline Pair 1 & SNA pre - SNA post & .46667 & 1.18723 & .30654 & 1.522 & 14 & .150 \\
\hline Pair 2 & SNB pre - SNB post & -3.13333 & .99043 & .25573 & -12.253 & 14 & $<.001^{* *}$ \\
\hline Pair 3 & ANB pre - ANB post & 3.66667 & .97590 & .25198 & 14.552 & 14 & $<.001^{* *}$ \\
\hline Pair 4 & WITS pre - WITS post & 3.46667 & .78982 & .20393 & 16.999 & 14 & $<.001^{* *}$ \\
\hline Pair 5 & $\begin{array}{l}\text { SN-MP pre - SN-MP } \\
\text { post }\end{array}$ & -1.26667 & 1.57963 & .40786 & -3.106 & 14 & .008 \\
\hline Pair 6 & $\begin{array}{l}\text { U1-NA pre - U1-NA } \\
\text { post }\end{array}$ & 2.10000 & 0.92933 & .83381 & 9.595 & 14 & $<.001^{* *}$ \\
\hline Pair 7 & L1-NB pre - L1-NB post & -4.60000 & 4.35562 & 1.12462 & -4.090 & 14 & $.001^{* *}$ \\
\hline Pair 8 & $\begin{array}{l}\text { mandibular length pre - } \\
\text { mandibular length post }\end{array}$ & -4.00000 & 1.06904 & .27603 & -14.491 & 14 & $<.001^{* *}$ \\
\hline Pair 9 & $\begin{array}{l}\text { maxillary length pre - } \\
\text { maxillary length post }\end{array}$ & -.33333 & .61721 & .15936 & -2.092 & 14 & .055 \\
\hline Pair 10 & $\begin{array}{l}\text { max-mand differential } \\
\text { pre-max-mand } \\
\text { differential post }\end{array}$ & -3.73333 & 1.33452 & .34457 & -10.835 & 14 & $<.001^{* *}$ \\
\end{tabular}
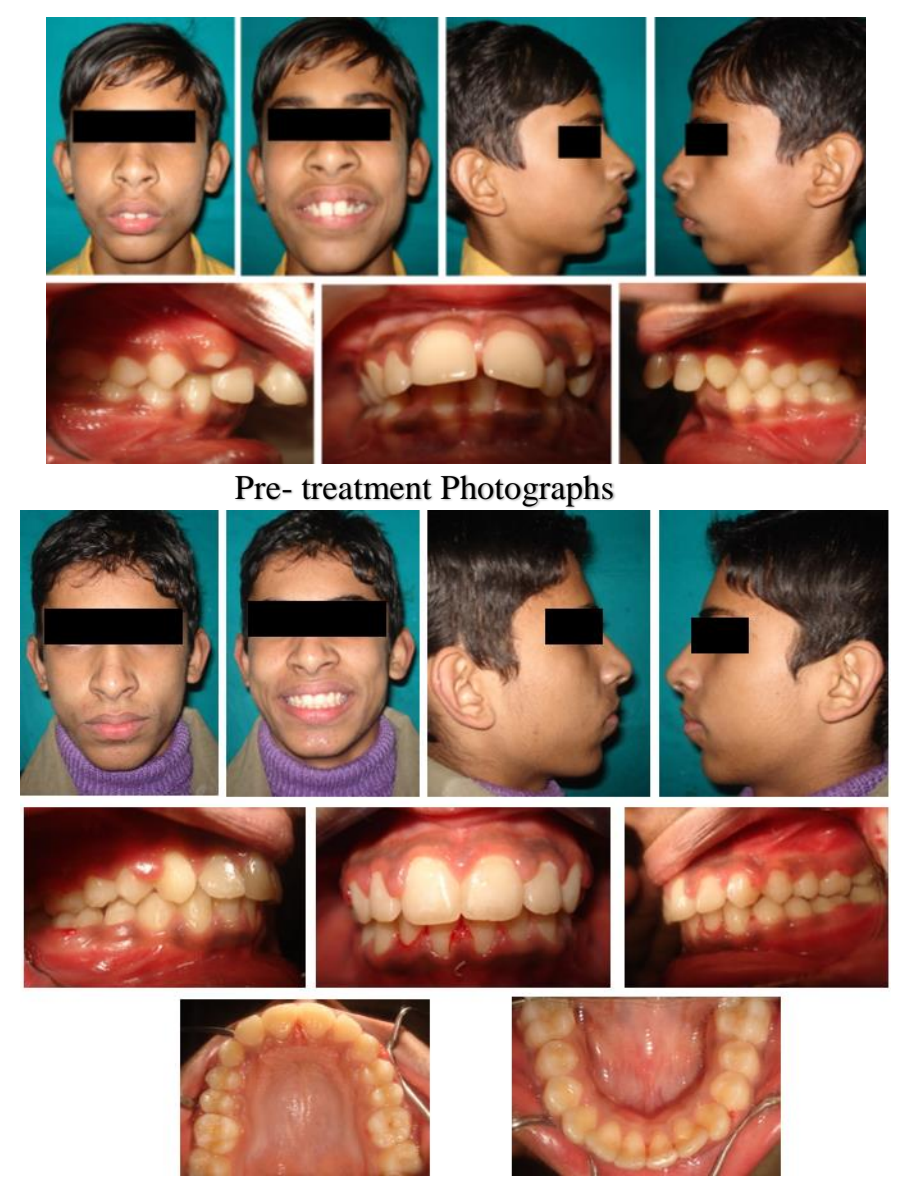

Post- treatment Photographs 
Fig. 1: Case 1

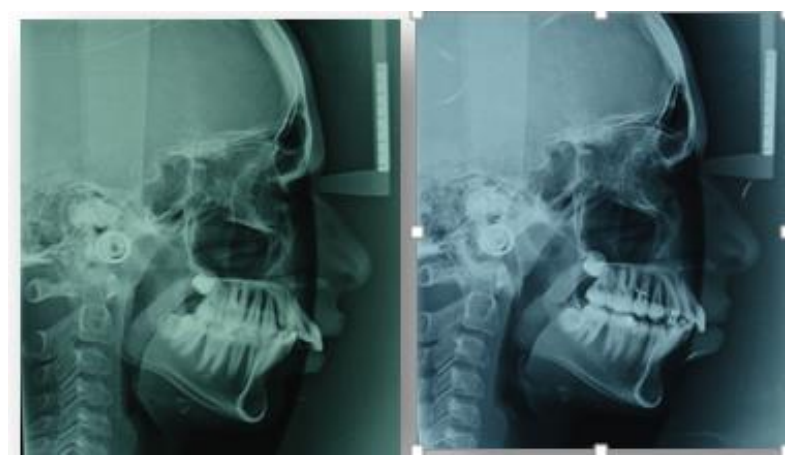

Pre- treatment \& Post -treatment Cephalogram
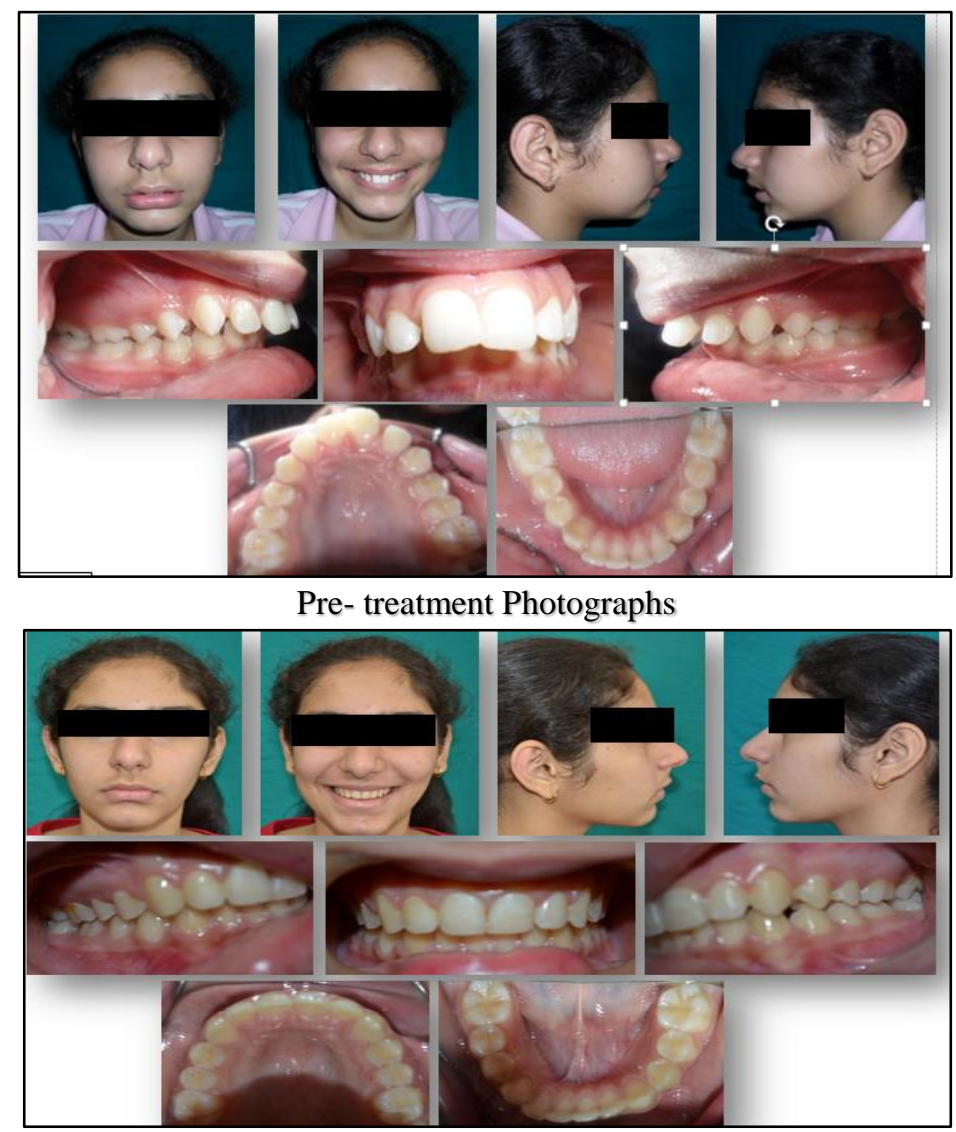

Post- treatment Photographs

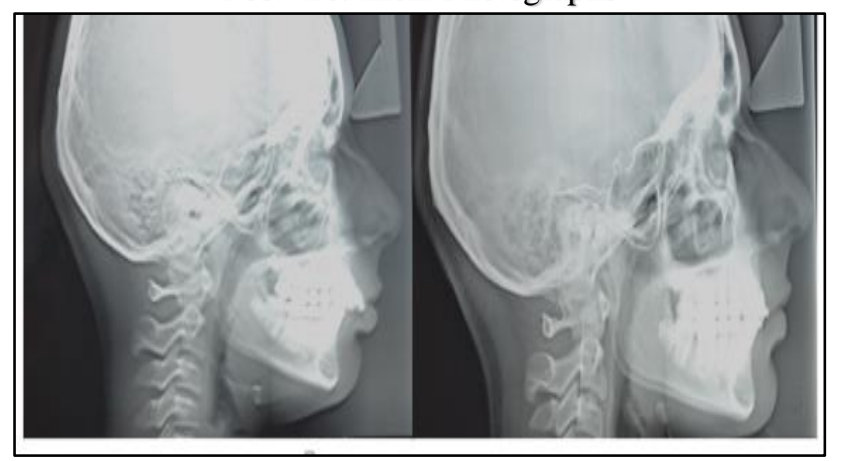

Pre- treatment \& Post -treatment Cephalogram

Fig. 2: Case 2 


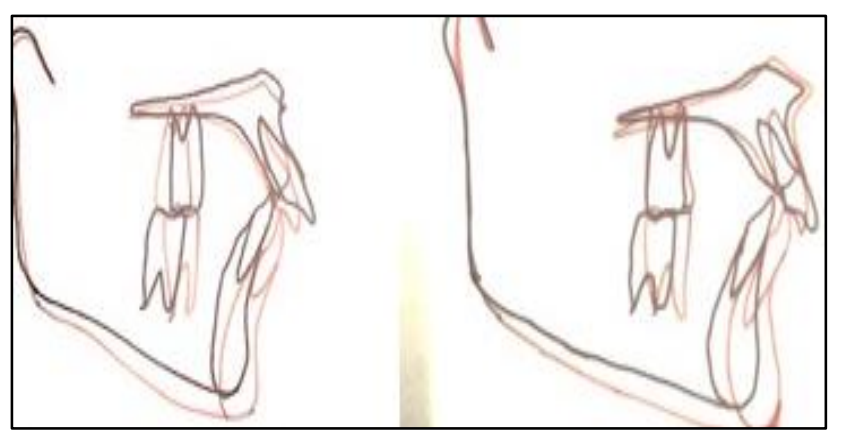

\section{Fig. 3: Superimposition}

\section{Discussion}

Facial aesthetics plays a vital role during social interactions and in dealing with people in society. It is the face that is noticed first during these interactions and a well- proportioned and attractive face is perceived as socially well acceptable.

Increased overjet, maxillary incisors trapping lower lip and a facial profile which is unfavourable are usually seen in cases with Class II malocclusion and this may predispose children to develop negative feeling towards their self-image and self-esteem. The orthodontic treatment aims towards achieving harmonious relationship of dentoskeletal components with a facial profile which is aesthetically pleasing.

Various treatment modalities have been discussed in literature for treating these patients. Functional appliances have been found to be a suitable treatment modality in growing individuals; which bring about the changes in the activity of the various muscle groups which influence the function and position of the mandible. ${ }^{23}$ Sagittally and vertically altering the mandibular position generates pressure by the muscle stretch. The resultant force thus generated gets transmitted to the underlying dental and skeletal tissues and thereby bring about the orthodontic and orthopedic changes. ${ }^{24}$

Twin Block is one of the most widely accepted functional appliance; being a simple, comfortable and aesthetically acceptable appliance which is designed in such a way that it enables maximizing the growth response to functional mandibular protrusion. The forces of occlusion are used as a functional mechanism to correct the malocclusion.

The aim of the Twin Block therapy is to induce supplementary lengthening of the mandible which is brought about by stimulating the growth at the condylar cartilage. Biological response of the condylar cartilage which is dependent on the growth rate of the mandible influences the effectiveness of the functional treatment. The rate of mandibular growth is not constant throughout the juvenile and adolescent stages. The duration, intensity and onset of pubertal spurt in mandibular growth varies in every individual. Evidence shows that the greatest effects of functional appliances is seen when the peak mandibular growth is taken into consideration while planning for functional appliances.

The sample enrolled in the study were selected from the total patient population of the clinic who were being subjected to treatment with Twin Block appliance, mainly on the basis of age and the presence of a skeletal Class II malocclusion with no other anomalies.

The growth effects of the Twin Block therapy were measured and it was found that the increase in mandibular length with Twin Block was pronounced and the rate of increase was dramatic. These responses were similar to those which were previously reported by various authors..$^{25,26}$

It was not possible to determine whether the increase in mandibular length (Co-Gn) was due to growth of mandible or a repositioning of the mandible. An improvement in the mandibular retrognathia could also be demonstrated by the increase in SNB by $3.13^{\circ}$; which also contributed to an improvement in the skeletal Class II relation. De Vinzenzo and Winn ${ }^{25}$ also found similar changes in their cephalometric study of functional appliances and their effects.

The forward growth of the maxilla was assessed by SNA and little change in SNA $\left(0.46^{\circ}\right)$ was found thus indicating little maxillary restraint. These changes did not suggest any significant headgear effect associated with the twin block appliance and this is in agreement with De Vinzenzo et al. ${ }^{8}$

The increase in the mandibular length result in a significant change in ANB and reduced the severity of Class II skeletal pattern.

Twin-block has a restraining effect on the upper molar which is demonstrated by slight molar distalization along with a significant forward movement of the lower molars; bringing about the correction of the Class II molar relation. The maxillary incisors are retroclined and the mandibular incisors are proclined, which contributes to the correction of the overjet along with forward growth/repositioning of the mandible.

There was also an increase in mandibular plane angle following treatment with $\mathrm{t}$ Twin Block appliance, which could be because of increased eruption of the lower molars during treatment after judicious trimming of the bite blocks. 


\section{Conclusion}

The following conclusions were drawn from the present study:

1. Correction of mandibular retrusion in the Class II malocclusion subjects by twin-block appliance was due to increase in the length of mandible by 4.4 $\mathrm{mm}$, measured at Co-Gn.

2. The significant increase in the SNB angle following correction of mandibular retrusion in Class II malocclusion subjects was found with the use of Twin Block appliance.

This study demonstrates that the Twin Block appliance is a very effective and efficient tool to treat subjects with Class II Div 1 malocclusion.

\section{References}

1. Cozza P, Baccetti T, Franchi L, De Toffol L, McNamara JA Jr. Mandibular changes produced by functional appliances in Class II malocclusion: A systematic review. Am J Orthod Dentofacial Orthop. 2006;129:599.

2. Baccetti T, Franchi L, Stahl F. Comparison of 2 comprehensive Class II treatment protocols including the bonded Herbst and headgear appliances: A double-blind study of consecutively treated patients at puberty. Am J Orthod Dentofacial Orthop. 2009;135:698.

3. Martins RP, da Rosa Martins JC, Martins LP, Buschang $\mathrm{PH}$. Skeletal and dental components of Class II correction with the bionator and removable headgear splint appliances. Am J Orthod Dentofacial Orthop. 2008;134:732-41.

4. Jena AK, Duggal R, Parkash H. Skeletal and dentoalveolar effects of twin block and bionator appliances in the treatment of Class II malocclusion: A comparative study. Am J Orthod Dentofacial Orthop. 2006;130:594-602.

5. Bjork A. The principal of the Andersen method of orthodontic treatment a discussion based on cephalometric x-ray analysis of treated cases. Am J Orthod.1951;85:125-34.

6. Hans Pancherz. A cephalometric analysis of skeletal and dental changes contributing class II correction in activator treatment. Am J Orthod. 1984;85(2):125-34.

7. Harris JE. A cephalometric analysis of mandibular growth rate. Am J Orthod. 1962;48:161-74.

8. DeVincenzo JP. Changes in mandibular length before, during and after successful orthopaedic correction of Class II malocclusions using a functional appliance. Am J Orthod Dentofac Orthop. 1991;99:241-57.

9. Windmiller EC. Acrylic splint Herbst appliance: cephalometric evaluation. Am J Orthod Dentofac Orthop. 1993;104:73-84.

10. Almeida MR, Henriques JF, Almeida RR, AlmeidaPedrin RR, Ursi W. Treatment effects produced by the bionator appliance. Comparison with an untreated Class II sample. Eur J Orthod. 2004;26:65-72.
11. Robertson NR. An examination of treatment changes in children treated with the functional regulator of Frankel. Am J Orthod. 1983;83:299-310.

12. DeVincenzo JP, Huffer RA, Winn MW. A study in human subjects using a device designed to mimic the protrusive functional appliances used previously in monkeys. Am J Orthod Dentofac Orthop. 1987;91:21324.

13. Nelson C, Harkness M, Herbison P. Mandibular changes during functional appliance treatment. Am J Orthod Dentofac Orthop. 1993;104:153-61.

14. Tulloch JFC, Medland W, Tuncay OC. Methods used to evaluate growth modification in Class II malocclusion. Am J Orthod Dentofac Orthop. 1990;98:340-47.

15. Cevidanes LHS, Franco AA, Gerig G, et al. Assessment of mandibular growth and response to orthopedic treatment with 3-dimensional magnetic resonance images. Am J Orthod Dentofacial Orthop. 2005;128:16-26.

16. Cevidanes LHS, Franco AA, Gerig G, et al. Comparison of relative mandibular growth vectors with highresolution 3-dimensional imaging. Am J Orthod Dentofacial Orthop. 2005;128:27-34.

17. Araujo AM, Buschang PH, Melo ACM. Adaptive condylar growth and mandibular remodelling changes with bionator therapy-an implant study. Eur J Orthod. 2004;26:515-22.

18. Malmgren O, Omblus J, Hägg U, Pancherz H. Treatment with an orthopaedic appliance system in relation to treatment intensity and growth periods. A study of initial effects. Am J Orthod Dentofacial Orthop. 1987;91:14351.

19. Hägg U, Pancherz H. Dentofacial orthopaedics in relation to chronological age, growth period and skeletal development. An analysis of 72 male patients with Class II division 1 malocclusion treated with the Herbst appliance. Eur J Orthod. 1988;10:169-76.

20. Martina R, Cioffi I, Galeotti A, et al. Efficacy of the Sander bite-jumping appliance in growing patients with mandibular retrusion: a randomized controlled trial. Orthod Craniofac Res. 2013;16:116-26.

21. Marsico E, Gatto E, Burrascano M, Matarese G, Cordasco G. Effectiveness of orthodontic treatment with functional appliances on mandibular growth in the short term. Am J Orthod Dentofacial Orthop. 2011;139:24-36.

22. D’Antò V, Bucci R, Franchi L, Rongo R, Michelotti A, Martina R. Class II functional orthopaedic treatment: a systematic review of systematic reviews. J Oral Rehabil. 2015;42:624-42.

23. Bishara SE, Ziaja RR. Functional appliances: a review. Am J Orthod Dentofacial Orthop. 1989 Mar;95(3):25058.

24. Proffit WR, Fields HW, Sarver DM. Contemporary Orthodontics. 5th ed. St. Louis: Mosby Elsevier. 2007.

25. DeVincenzo JP, Winn MW. Orthopaedic and orthodontic effects resulting from the use of a functional appliance with different amounts of protrusive activation. Am J Orthod Dentofac Orthop. 1989;96:181-90.

26. Mills C M. Treatment effects of the twin block appliance: A cephalometric study. Am J Orthod Dentofacial Orthop. 1998;114:15-24. 